\title{
Conservation status and reproductive ecology of giant babax Babax waddelli (Aves, Timaliinae), endemic to the Tibet plateau
}

Xin Lu

\begin{abstract}
The Lower Risk/near threatened giant babax Babax waddelli is endemic to southern Tibet. The babaxes, living in groups of 3-8 individuals year-round, favoured edge habitats in forest regions where the group encounter rate during the breeding period was 0.35 groups $\mathrm{h}^{-1}$ and population density 0.04 birds ha $^{-1}$, and in scrub regions they depended on the patches covered with higher bushes in which the group encounter rate and population density were 0.32 groups $\mathrm{h}^{-1}$ and 0.03 birds $\mathrm{ha}^{-1}$ respectively. The global population of the babaxes was estimated to be 120,000 birds. Reproductive and behavioural data were collected from scrub environments in a valley. Egg laying occurred between early May and early June, and clutch size ranged from 2 to 4 eggs, 2.9 on average. Incubation and fledging lasted 16-18 days respectively. Nesting success, measured as the proportion of clutches from which at least one young survives to fledging, was $75 \%$. Some of the babax's nests were cooperatively attended by group members and the
\end{abstract}

others only by both parents. The most preferable nesting areas were in dense bushes more than $1.8 \mathrm{~m}$ in height (mainly Rosa sericea, Berberis hemleyana, Cotoneaster divaricatus, Sibiraca angustata and Salix sclerophylla). Such strong dependence on high bushes leaves babaxes more susceptible to vegetation degradation. As a result, the increasing clearance of scrub habitats for firewood is a major current threat to the birds around the mid-Yalong Zangbo River, a region with the densest human population and most rapidly developing economy in Tibet. Their naturally low population density and strongly social grouping behaviour present extra risk factors that have to be taken into account. The importance of vegetation protection for long-term survival of this endemic species is highlighted.

Keywords Babax waddelli, conservation, giant babax, mating system, mid-Yalong Zangbo River, nest-site selection, status, Tibet.

\section{Introduction}

Giant babax Babax waddelli (Aves, Timaliinae) is a characteristic species of the Southern Tibet Endemic Bird Area (Stattersfield et al., 1998). The range of giant babax is largely confined to the mountains around the midYalong Zangbo River that extend from the Lhasa River east to the Nu River (Zheng et al., 1983, 1987). The giant babax is found at altitudes of 3,000-4,500 $\mathrm{m}$ and is one of several Timaliinae species adapted to dry cold alpine climates, in contrast to most members of this family, which are more typical of the subtropics and tropics (Zheng et al., 1987). The species is categorized as Lower Risk/near threatened on the IUCN Red List (IUCN, 2003). Currently, apart from a few distribution records (Li, 1984), there is little information on the species' ecology and conservation status.

Xin Lu Department of Zoology, College of Life Sciences, Wuhan University, Wuhan 430072, China. E-mail luxinwh@public.wh.hb.cn

Received 22 April 2003. Revision requested 22 August 2003. Accepted 10 June 2004
The existing alpine vegetation around the mid-Yalong Zangbo River includes forest and scrub (Zhang, 1988). Historically, the scrub vegetation was formed as a result of forest degradation due to the increasing aridity that accompanied the rise of the Himalayas (Li, 1988; Miehe, 1996). At present this region has the largest human population and the most rapidly developing economy in Tibet, and the montane vegetation is suffering from increasing pressure from human activities, especially use of scrub for fuelwood (Niu, 1999; Winkler, 2000). During the last 50 years as much as one-third of the scrub vegetation has been lost from the Lhasa mountains (Li et al., 2001).

Knowledge of the relationship between a bird and its habitat can contribute to an understanding of the adaptation of a species to its environment (Cody, 1985), and the social behaviour of threatened species is also of importance for planning habitat management (Primack, 1993). Here I provide for the first time information on the babax's status, reproduction, nest-site selection and social organization, to improve our knowledge of the species' ecology and the impact of habitat degradation on the species. 


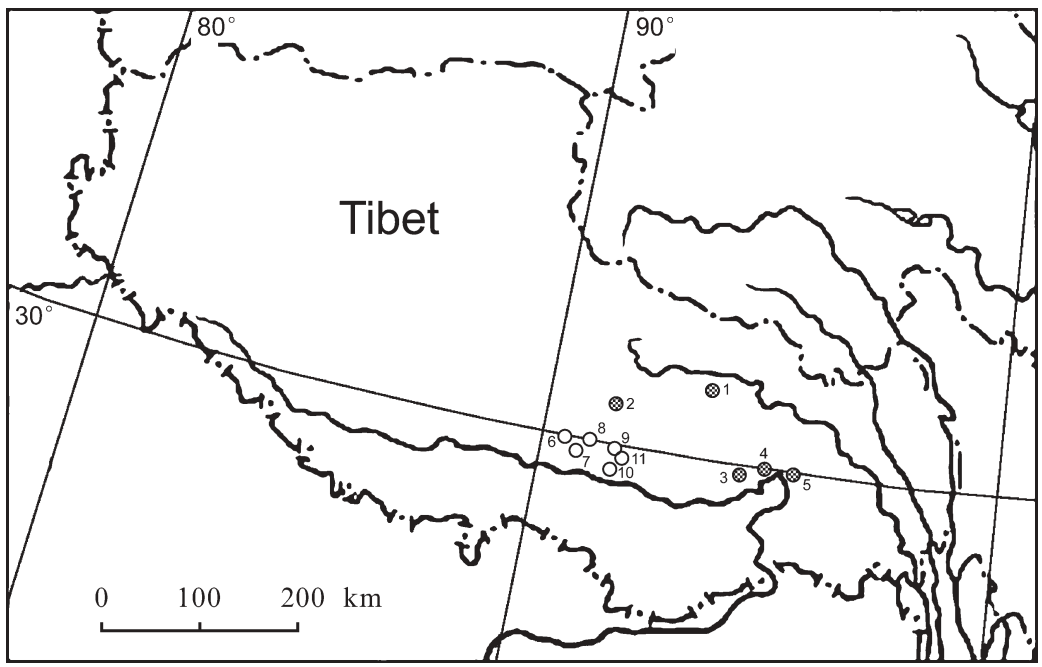

Fig. 1 The location of the 11 sample sites (see Table 1 for details) on the eastern Tibetan plateau. Shaded circles are sites in forest areas: 1, Sa Wang; 2, Rezhen monastery; 3, Bajie nature reserve; 4 , Dongiiu nature reserve; 5, Duoji. Open circles are sites in scrub areas: 6, Eastern suburbs of Lhasa city; 7 , Southern suburbs of Lhasa city; 8, Qushui; 9, Sibu; 10, Qingpo; 11 , Xiongse.

Table 1 The eleven sites, with altitude and habitat type, surveyed for the giant babax, with survey dates, total survey time, group size of located birds, and group encounter rate and population density.

\begin{tabular}{|c|c|c|c|c|c|c|c|}
\hline Location & $\begin{array}{l}\text { Altitude } \\
(\mathrm{m})\end{array}$ & Habitat & Survey dates & $\begin{array}{l}\text { Total } \\
\text { survey } \\
\text { time (h) }\end{array}$ & $\begin{array}{l}\text { Group } \\
\text { size }\end{array}$ & $\begin{array}{l}\text { Group } \\
\text { encounter } \\
\text { rate (groups } \\
\mathrm{h}^{-1} \text { ) }\end{array}$ & $\begin{array}{l}\text { Population } \\
\text { density } \\
\left(\text { birds ha }{ }^{-1}\right)\end{array}$ \\
\hline \multicolumn{8}{|l|}{ Forest areas } \\
\hline 1. Sa Wang & 3,800 & Primary forest edge & May-August 1995 & 32 & $4-7$ & 0.13 & 0.01 \\
\hline 2. Rezhen monastery & 4,100 & Primary forest edge & September 1999 & 3 & $6-7$ & 0.67 & 0.07 \\
\hline 3. Bajie nature reserve & 3,100 & Primary forest edge & May 2001 & 4.5 & 6 & 0.22 & 0.02 \\
\hline $\begin{array}{l}\text { 4. Dongiiu nature } \\
\text { reserve }\end{array}$ & 2,800 & Primary forest & May 2001 & 7 & - & - & - \\
\hline 5. Duoji & 3,020 & Secondary forest and scrub & May 2001 & 2.5 & 5 & 0.40 & 0.03 \\
\hline \multicolumn{8}{|l|}{ Scrub areas } \\
\hline $\begin{array}{l}\text { 6. Eastern suburbs of } \\
\text { Lhasa city }\end{array}$ & 3,650 & Riverbank with woodland & April-May 1996 & 12 & - & - & - \\
\hline $\begin{array}{l}\text { 7. Southern suburbs of } \\
\text { Lhasa city }\end{array}$ & 3,800 & Mountains with low scrub & April-July 1996, 1999 & 20 & - & - & - \\
\hline 8. Qushui & 4,200 & Mountains with tall scrub & September 1998 & 11 & $6-7$ & 0.27 & 0.03 \\
\hline 9. Sibu & 3,750 & Riverbank with natural scrub & May 2001 & 6 & - & - & - \\
\hline 10. Qingpo & 4,100 & Mountains with tall scrub & June 2001 & 4 & $6-8$ & 0.50 & 0.06 \\
\hline 11. Xiongse & 4,200 & Mountains with tall scrub & $\begin{array}{l}\text { April-July 1999-2000, } \\
\text { April-September } \\
\text { 2001-2002 }\end{array}$ & 31 & $3-6$ & 0.19 & 0.01 \\
\hline
\end{tabular}

\section{Study area}

I visited 11 sites (Fig. 1, Table 1) within the species' range during spring and early summer over 1995-2004. The sites were in forest areas in eastern Tibet (at 2,800$4,100 \mathrm{~m}$ altitude, with a total annual precipitation of 600 $880 \mathrm{~mm}$ ) and scrub areas in southern Tibet (at altitudes $>3,650 \mathrm{~m}$, with a total annual precipitation of 450$580 \mathrm{~mm}$ ) (Table 1). Dominant plant species in forest areas include halfour spruce Picea likiangensis on the northfacing slopes, and hollyleaf-like oak Quercus aquifolioldes and Tibetan juniper Sabina tibetica on the south-facing slopes. Scrub vegetation around forest edges consists mainly of rose Rose sericea and barberry Berberis hemleyana. There are forest plantations at some of the sites, and these are dominated by poplar Populus spp. and willow Salix spp.

Detailed ecological data on the species were collected at one of the 11 sites, a c. 400 ha area of scrub in the Xiongse Valley near Lhasa (Figs. 1 \& 2) over 1996-2004. This site has an altitude range of 3,800-5,600 m, an annual average temperature of $4.5^{\circ} \mathrm{C}$ and a total annual precipitation of $566 \mathrm{~mm}$ (over $90 \%$ of which falls during June-September), and is characterized by alpine shrubs and meadows. On the southern slopes of the valley, rose and barberry are found at 4,000-4,500 $\mathrm{m}$, and Wilson juniper Sabina pingii at 4,500-4,900 m. On the northern slopes spiraea Spirace alpina occurs at 4,000-4,200 m 


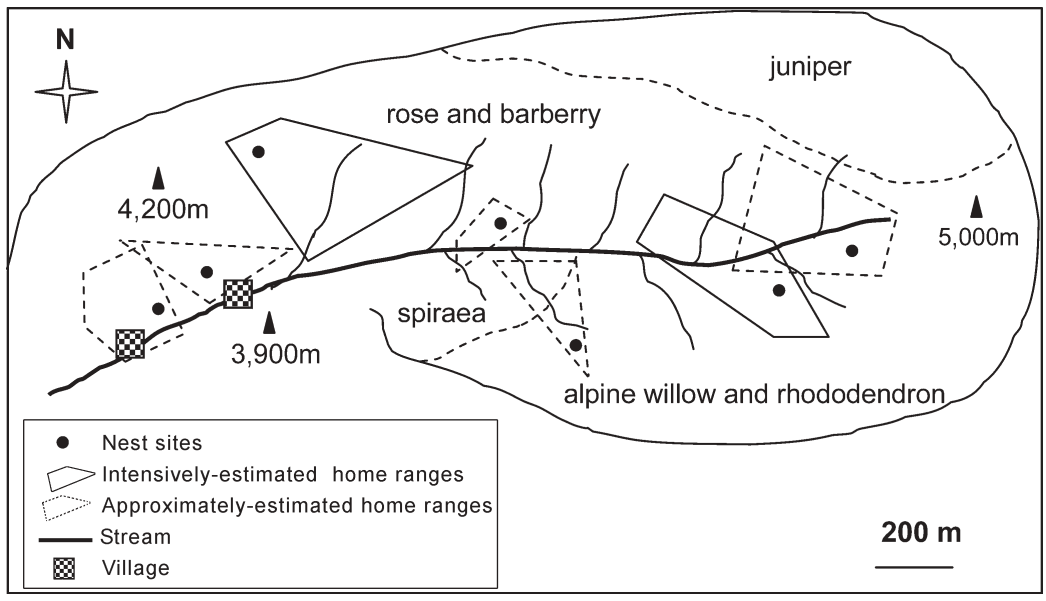

Fig. 2 Xiongse Valley in the Lhasa mountains (site 11 on Fig. 1), showing the locations of the giant babax's nest sites and locations of their home ranges. and alpine willow Salix sclerophylla and rhododendron Rhododendron spp. at $4,200-4,900 \mathrm{~m}$. Alpine meadow is predominant at $4,900-5,200 \mathrm{~m}$. No hunting or agriculture have been carried out in this area.

\section{Methods}

At each of 11 sites visited I randomly set up 1-3 transects of 3-6 km length across the altitudinal range of a specific vegetation type, and counted babaxes encountered either side of the transect, which was walked at a speed of $1.5 \mathrm{~km} \mathrm{~h}^{-1}$ in the morning. A total of $133.5 \mathrm{~h}$ were spent in surveying a total of 21 transects at the 11 sites. The babax's unique calls could be heard at a distance of $200 \mathrm{~m}$ and their behaviour made it easy to locate and count birds, even in dense understorey, leading to little if any variation in detectability in the different habitat types surveyed. Because of the scattered occurrence of babax groups, small group sizes, and the low likelihood of missing any groups within the range of detectability (assumed to be $200 \mathrm{~m}$ either side of each transect) their abundance could adequately be estimated by line census methods (Bibby et al., 1992). At some sites it was difficult to estimate exact distances to birds because of complex topography and dense vegetation cover, and I therefore used the fixed-width line transect method to provide comparable abundance data among sites (Bibby et al., 1992). Based on the estimated densities and the areas of existing vegetation in the species' range (Zhang, 1988), an estimate was made of the approximate global population size for the species.

During the breeding seasons of 1996, 1999-2001 and 2004, babax nests were opportunistically located in Xiongse Valley. Once a nest was located, I took measurements of the nest, eggs and nestlings, and monitored the nest to determine length of incubation, time to fledging, nestling growth and reproductive success. For clutches located when incubation had already begun or nestlings had hatched, I determined egg-laying dates by back dating using the reproductive parameters obtained from clutches for which complete data were obtained. Incubation and caring behaviour were observed from a hide to reduce disturbance to breeding birds. I also noted babax behaviour and counted the groups encountered to assess the dynamics of their social organization.

During the 2002 breeding season I made systematic searches for all possible babax nests throughout Xiongse Valley to determine the spatial distribution of the home ranges of all babax groups within the valley. Babaxes are typically gregarious, occurring in social family groups throughout the year, and the activities of individual groups could be readily observed in the relatively sparse vegetation. Therefore, although no bird was marked or tagged, group home ranges could reliably be identified. Of the six family groups located, two were intensively studied and their positions regularly recorded using a Global Positioning System. These positions were then plotted and the positions for each group were connected to form a minimum convex polygon, from which home range size of the group was obtained. Using relatively fewer positions the approximate home ranges of the four other groups were estimated.

After a nesting attempt finished, the nest site characteristics were noted: altitude, slope direction and angle, height of the plant used for nesting, distance to water (streams) and vegetation characteristics associated with the nesting area. Vegetation cover within an area of $10 \times 10 \mathrm{~m}$ area around the nest site was recorded as: dense (scored as 2) if the proportion of higher bushes $(\geqslant 1.5 \mathrm{~m})$ was $>50 \%$, or sparse (scored as 1$)$ when the proportion was $<50 \%$. The mean percent cover of herbs was measured within four $1 \times 1 \mathrm{~m}$ quadrats. To increase the sample size, I also recorded the same information for previously used babax nest sites. The old nests were 
distinguishable from those of other bird species occurring in the study area by their unique shape, size and materials. A total of 23 nest sites, 12 active and 11 old, were described. To assess the availability of nesting habitats, I randomly chose 23 sites within the habitats where the babaxes nested and made the same measurements as at nest sites. A stepwise discriminate function analysis (Johnson \& Wichern, 1992; Manly, 1998) using the characteristics of nest and random sites was used to determine which variables were the best predictors of a babax nest site. Discriminant function analysis can be used to determine whether two groups (e.g. nest and random sites) differ with regard to characteristic variables, and the variables used to predict group membership. The larger the discriminant function coefficient of a variable, the larger is the variable's unique contribution to the discrimination between groups. Prior to analysis the data were natural log-transformed to improve normality. All statistical tests are two tailed.

\section{Results}

\section{Habitat preference, abundance and status}

Babaxes are resident throughout their range, of which forest and scrub habitats account for 71.9 and $28.1 \%$, respectively. In forest areas babaxes were mainly found in edge habitats with tall dense scrub vegetation (Table 1), suggesting that they are a typically scrubadapted species. In scrub areas only the larger, continuous patches with bushes $>1.5 \mathrm{~m}$ tall were used by the birds. As a result, suitable habitats were restricted to the inside of valleys. Within their preferred habitats the birds occur from 2,800 to $4,500 \mathrm{~m}$. I never saw babaxes in woodland plantations in spite of extensive survey effort in such habitat.

The babaxes lived in groups all year round. Mean group size in forest areas $(5.50 \pm \mathrm{SE} 0.42$, range $4-7$, $\mathrm{n}=8)$ did not differ significantly from that $(5.36 \pm \mathrm{SE}$ 0.45 , range $3-8, n=11$ ) in scrub areas (Mann-Whitney $\mathrm{U}$ test, $z=-0.26, \mathrm{P}=0.80$ ). The mean encounter rate of groups in forest edges during the breeding period was $0.35 \pm$ SE 0.12 groups $^{-1}$ (range $0.13-0.67, \mathrm{n}=4$ sites) and the population density $0.04 \pm$ SE 0.01 birds ha $^{-1}$ (range 0.01-0.07). The corresponding figures in selected scrub habitats were $0.32 \pm$ SE 0.09 groups $\mathrm{h}^{-1}$ (range $0.19-0.50, \mathrm{n}=3$ sites $)$ and $0.03 \pm$ SE $0.02(0.01-0.06)$ birds $\mathrm{ha}^{-1}$, with no significant difference from those in forest areas (Mann-Whitney $\mathrm{U}$ test, $z=0.00, \mathrm{P}=1.00$ ). By respectively multiplying the densities with the total areas of suitable vegetation in forest $(2,300,000 \mathrm{ha})$ and scrub (900,000 ha) that the species occupies (Zhang, 1988), I obtained an approximate global population estimate of 120,000 birds.

\section{Breeding season, nest, egg, nestling and breeding success}

Of the 12 active nests located at Xiongse Valley during this study, three had their first eggs in early May, four in mid May, three in late May and two in early June. Investigations in April and during late June to September did not detect any nesting attempts, suggesting that the laying period of the population lasted only 1 month.

The babaxes built a cup shaped nest between branches in bushes, which had a mean outer diameter of $20.3 \pm \mathrm{SE}$ $1.4 \mathrm{~cm}$ (range 16-28, $\mathrm{n}=10$ ), an inner mean diameter of $11.7 \pm$ SE $0.4 \mathrm{~cm}$ (range 10-14), a mean depth of $7.4 \pm \mathrm{SE}$ $0.7 \mathrm{~cm}$ (range 6-11) and a mean height of $15.7 \pm \mathrm{SE} 2.1 \mathrm{~cm}$ (range 10-23). The exterior of the nests was woven with thicker twigs and peeled bark from bushes, the interior with thinner twigs and roots of plants; no soft materials were found in the nests. The eggs were solid light blue or with a few scattered light brown spots. The mean size of 18 eggs was $32.5 \pm$ SE $0.3 \mathrm{~mm}$ (range 29.6-34.0) in length and $22.0 \pm \mathrm{SE} 0.1 \mathrm{~mm}$ (range 21.0-22.8) in breadth, and fresh mass of three eggs was 8.2-8.9 $\mathrm{g}$. Average clutch size was $2.9 \pm$ SE 0.2 (range $2-4, n=9$ ), with 3 being most common $(67 \%)$.

Incubation lasted 16-18 days $(\mathrm{n}=3)$ during which each egg lost $0.09 \mathrm{~g}$ of its mass per day on average. Hatchlings, weighing about $7 \mathrm{~g}$, had a naked skin, which was dark grey on the back and pink on the abdomen, with a few white downs (c. $7 \mathrm{~mm}$ long) on inner orbits, occipital, humeral, low spinal and femoral tracts. Fledging period was $16-18$ days ( $\mathrm{n}=2$ clutches) and young left the nest when they were c. $85 \mathrm{~g}, 60 \%$ of the adult mass. For two nestlings in a nest, growth rate constants of logistic equations for body mass were 0.42 for the larger and 0.33 for the smaller. Of 26 eggs, four were deserted for unknown reasons, two were eaten by a magpie Pica pica, one was infertile, two had an embryo that died and the remaining 17 (65\%) hatched successfully. Of 12 nesting attempts, nine $(75 \%)$ had at least one young survive to fledging.

\section{Social and parental behaviour}

Seasonal change in social group size and group activities The babaxes were commonly encountered in groups all year round (Tables $1 \& 2$ ). During the nesting period occurrence of solitary or pairing individuals were associated with breeding behaviours (pairing, incubating or caring for young). After reproduction all individuals stayed in groups, which became larger as newly-born young joined.

Babaxes frequently foraged on the ground and often dug into the soil. When perching they tended to take up position on the highest branches of a bush and called continuously and loudly. On five occasions I watched 
Table 2 Seasonal change in frequencies of giant babax groups of different sizes encountered in Xiongse Valley (see Fig. 1 for location). The data from four years (1999-2002) were pooled and samples may include some groups counted more than once.

\begin{tabular}{|c|c|c|c|c|c|c|}
\hline \multirow[b]{2}{*}{ Group size } & \multicolumn{6}{|l|}{ Month } \\
\hline & April & May & June & July & August & September \\
\hline 1 & 2 & 1 & 1 & & & \\
\hline 2 & 1 & 4 & 4 & & & \\
\hline 3 & 1 & 3 & 3 & & & \\
\hline 4 & 1 & 4 & 3 & 2 & 1 & \\
\hline 5 & & 2 & 1 & 2 & 1 & \\
\hline 6 & 4 & 1 & 1 & 1 & 1 & 1 \\
\hline 7 & & & & & 1 & 3 \\
\hline 8 & & & & & & 1 \\
\hline Mean \pm SE & $3.9 \pm 0.7$ & $3.3 \pm 0.4$ & $3.2 \pm 0.4$ & $4.8 \pm 0.4$ & $5.5 \pm 0.6$ & $7.0 \pm 0.3$ \\
\hline
\end{tabular}

two individuals preening one another. Each social group moved within its home range, which included different types of vegetation (Fig. 2). In the 2002 breeding season there were a total of 26 individuals in five groups within the Xiongse Valley (not including the two groups occurring near the villages located at the edge of the valley, Fig. 2). Home ranges of the two family groups that were studied intensively in 2002 were 19.9 and 14.8 ha, respectively (Fig. 2). Daily movement routes of a group often included their entire home range, with a maximum daily movement of $300-400 \mathrm{~m}(\mathrm{n}=3)$. Groups appear to exhibit fidelity to their home range. A group was found to roost in the same high dense bush patch for at least two nights, and several active and previously-used nest-sites were close to each other (mean 18.2 \pm SE $7.8 \mathrm{~m}$, range $0-70, \mathrm{n}=9$ cases), with two active nests being built on top of the old one. On one occasion I observed the meeting of two groups; the members chirped noisily for c. 15 minutes, seeming to defend their own home ranges.

\section{Incubation and provisioning behaviour}

There were two patterns of social paternal care. (1) Socially-assisted clutches $(\mathrm{n}=7)$. In $21 \mathrm{~h}$ of observation at five nests there were seven records of 3-4 individuals visiting the same nest during incubation, and during 10 of 16 checks at four nests, 3-6 individuals defended the nest by violently calling when I checked the nestlings. I witnessed three adult babaxes at a nest attacking a passing Tibetan partridge Perdix hodgsoniae. During incubation or rearing of young, group members were regularly seen 100-200 m from their nests, often calling loudly to each other. (2) Parentally-assisted clutches $(\mathrm{n}=5)$. There were never more than two individuals seen incubating (6.5 h of observation at two nests) or taking care of nestlings ( $6 \mathrm{~h}$ of observation for two nests and 19 nest checks for three nests).

Regardless of the type of paternal care, only one individual was seen during periods of incubation and no courtship feeding behaviour was witnessed during $21.5 \mathrm{~h}$ of observations. When taking over incubation duty, one individual came silently to the nest. The transfer of incubation duty between individuals was immediate, ensuring the eggs were attended continuously, except for one case of a babax being absent from a nest. For a given nest, the length of incubation bouts varied greatly, some being short $(8.2 \pm \mathrm{SE} 1.0 \mathrm{~min}$, range 4-15, $\mathrm{n}=11)$ and some long $(36.8 \pm$ SE $5.0 \mathrm{~min}$, range 22-80, $\mathrm{n}=12$ ). When nestlings were $<10$ days old they were continuously brooded. Observations of a nest containing two 8-day old nestlings showed that babaxes alternately returned to the nest, and after feeding the nestlings, took over brooding duty. In a few cases, food was first transferred to the brooding birds, who then fed the nestlings. Individual mean brooding period was $17.8 \pm \mathrm{SE} 3.2 \mathrm{~min}$ (range $4-55, \mathrm{n}=18$ ). For both socially- and parentallyassisted clutches, I found that on each occasion only one bird went back to the nest, fed the nestlings and then took over brooding duty. Cooperative nest defence behaviour took place only when the nestlings were in great danger.

\section{Nest site choice}

Among 23 nest sites located, one was in a poplar tree Populus platyphylla and another in Tibetan seabuckthorn Hippophae tibetica near villages at the edge of the valley; the remaining 21 occurred in alpine vegetation, six on the northern slopes covered with willows and 15 on the southern slopes covered with bushes. The 23 nests were found from $3,800 \mathrm{~m}$ at the foot of the mountain to $4,450 \mathrm{~m}$ near the willow treeline. All the scrub plants used as nest sites were the tallest within the local plant community (Table 3). For specific plant species the individual bushes selected were taller and denser, and more likely to occur in a larger patch $(\geqslant 50 \times 50 \mathrm{~m})$ with higher vegetation. The stepwise discriminant function analysis produced one significant function that accounted for $100 \%$ of the variability (Table 4). The standardized discriminant function coefficients indicated that area of scrub patch, 
Table 3 A comparison of the heights of giant babax nests off the ground in eight nesting plants, and height of 50 randomly selected plants in Xiongse Valley (see Fig. 1 for location).

\begin{tabular}{lllll}
\hline Plant species & Sample size & $\begin{array}{l}\text { Height of nest from } \\
\text { the ground }(\mathrm{cm})\end{array}$ & $\begin{array}{l}\text { Height of nesting } \\
\text { plant }(\mathrm{cm})\end{array}$ & $\begin{array}{l}\text { Average height of randomly } \\
\text { selected plant (range) }(\mathrm{cm})\end{array}$ \\
\hline $\begin{array}{l}\text { Rosa sericea } \\
\text { Berberis hemleyana }\end{array}$ & 3 & $150-190$ & $290-310$ & $162.6(125-320)$ \\
Cotoneaster divaricatus & 5 & $90-150$ & $170-290$ & $159.1(112-255)$ \\
Lonicera angustifolia & 4 & $90-160$ & $210-320$ & $227.1(145-320)$ \\
Salix sclerophylla & 1 & 126 & 180 & $159.4(55-210)$ \\
Sabina tibetica & 6 & $141-230$ & $360-500$ & $315.3(200-650)$ \\
Populus platyphylla & 1 & 178 & 320 & - \\
Hippophae tibetica & 1 & 210 & 1,200 & - \\
\hline
\end{tabular}

Table 4 Summary of stepwise discriminate function analysis of the habitat characteristics measured at babax nest sites $(n=23)$ and random sites $(\mathrm{n}=23)$.

\begin{tabular}{lc}
\hline & $\begin{array}{c}\text { Discriminate } \\
\text { function I }\end{array}$ \\
\hline Eigenvalue & 1.6192 \\
\% eigenvalue associated with the function & 100.0 \\
Chi-square statistic & 31.69 \\
Significance (degrees of freedom) & $\mathrm{P}<0.001(2)$ \\
Standardized discriminate function coefficients & -0.1129 \\
Altitude & -0.6989 \\
Slope direction* & -0.1402 \\
Slope degree & 0.5110 \\
Nesting plant height* & 0.5618 \\
Size of scrub patch* & -0.3271 \\
Abundance of meadow & -0.1025 \\
Distance to water & \\
\hline
\end{tabular}

*Variable significantly contributing to discriminating power.

slope direction and nesting plant height distinguish babax nest sites from random selected sites.

\section{Discussion}

The 1-month reproductive season of highland babaxes is markedly shorter than for lowland Timaliinae species. For example, it is 4 months for arrowmarked babbler Turdoides jardineii in South Africa (Monadjem et al., 1995) and red-billed leiothrix Leiothrix lutea in Hawaii (Ralph et al., 1998), 6 months for Taiwan yuhinas Yuhinas brunneiceps in Taiwan (Yuan \& Liu, 1998), 7 months for common babbler Turdoidae caudatus (Gaston, 1978b) and 10 months for jungle babbler Turdoides striatus (Gaston, 1978c). In the Lhasa mountains the vegetation begins to dieback after mid July, which may limit further nesting attempts. As babaxes needed to spend c. 40 days raising a clutch, it is unlikely that a pair will produce more than one clutch per season.

I observed a higher nesting success $(75 \%)$ for giant babaxes than reported for most other Timaliinae species.
In Taiwan yuhinas it is $42 \%$ (Yuan \& Liu, 1998), in David's laughing thrush Garrulax davidi 40\% (Yang \& Li, 1998), in common babbler 57\% (Gaston, 1978b), and in jungle babbler $40 \%$ (Gaston, 1978c). There are two possible reasons for this. Firstly, my study area had a low diversity and density of potential predator species (only magpies, grey-backed shrike Lanius tephronotus and Siberian weasel Mustela sibirica) and thus a low predation pressure compared to subtropical or tropical areas, which can support more abundant predator faunas. This supports the idea that high reproductive success results from low predation pressure (Badyaev, 1997). Secondly, cooperative nest defence could reduce the risk of predation. The assistance of non-breeding group members contributes substantially to the success of breeding pairs in the Arabian babbler Turdoides squamiceps (Wright, 1998).

Evidence from almost all the Timaliinae species already investigated (Gaston, 1977, 1978a,b,c; King, 1980; Zahavi, 1990; Yuan \& Liu, 1998) indicates that they have a highly social organization and a cooperative breeding system. The fact that giant babaxes lived in groups all year-round and that group members attended the same nests indicates they are also cooperative breeders. Brown (1987) and Emlen (1997) concluded that cooperative breeding is widespread among birds in subtropical and tropical regions of the world, but it is less common in highland temperate species.

Yuan \& Liu (1998) reported that in cooperatively breeding Taiwan yuhinas, more than one female laid in the same nest so that larger clutches of 4-8 eggs were common. All the giant babax nests I visited contained 2-4 eggs, smaller than the usual clutch size of 4-5 eggs of lowland Timaliinae species (Zheng et al., 1987). This indicated, as with several well-studied congeners (Gaston 1978c; Brown et al., 1983; Zahavi, 1990), that each babax group contained a single breeding pair and only one female was involved. Therefore, giant babax groups should be, according to Elmlen's (1997) definition, a simple family, compared to the extended family (e.g. 
Taiwan yuhinas, Yuan \& Liu, 1998) in which two or more group members of one or both sexes participate in reproduction simultaneously. Some giant babax nests were attended by group members and the others by only both parents. Similar intraspecific variations in mating system have been reported in common babbler (Gaston, 1978b), as well as in other bird species (e.g. scrub jays Aphelocoma; Emlen, 1978).

My results showed that even in their preferred habitats, giant babaxes had a low population density $\left(0.03-0.04\right.$ birds $\left.h^{-1}\right)$, as against $>2$ birds $h^{-1}$ for Henry's laughing thrush Garrulax henrici (X. Lu, unpubl. data), a symbiotic Timaliinae species endemic to the Tibet plateau.

Because giant babaxes may occur across a wide range of altitudes (Table 1, Figs. $1 \& 2$ ) and because the edge habitats they favour are widespread from the foot of the mountains to the treeline, the populations inhabiting primary forest in eastern Tibet would be expected to face few threats. In scrub regions, although woodland plantations along riverbanks have been established for $>20$ years and provide good shelter, I found no evidence of babax using these habitats for either shelter or breeding. This giant babax appears to depend on natural vegetation, in which they require relatively tall bushes for perching and nesting. Unfortunately, the tallest bushes in areas of scrub vegetation are more likely to be cut for fuelwood, and as a result scrub cover has become poor near villages, in which areas babaxes have completely disappeared. Even in the inside of valleys, such as Xiongse, taller vegetation in some areas had been cut by local people. Under the more severe alpine climatic conditions around the mid-Yalong Zangbo River, it takes at least 15-20 years for cut bushes to grow as high as those suitable for babax nesting (X. Lu, unpubl. data). In areas where vegetation has suffered intensive degradation, restoration is almost impossible. Babaxes in scrub regions were thus restricted to isolated and fragmented habitats. Moreover, several symbiotic species such as rufous turtle dove Streptopelia orientalis, grey-backed shrike and Henry's laughing thrush, had overlapping reproductive periods and similar demands for nest site plants to those of giant babaxes; for each species $>80 \%$ of nests were found in the same species of plants used by babaxes (X. Lu, unpubl. data). Decline of tall vegetation will probably increase interspecific competition for the preferred individual plants. Cooperative breeding behaviour, longer daily travel and strong home range fidelity render babaxes more vulnerable to vegetation degradation. All these facts emphasize the importance of protection and management of alpine scrub vegetation around the mid-Yalong Zangbo River for long-term survival of the endemic giant babax.

\section{Acknowledgements}

I wish to thank the Buddhists in Xiongse nunnery for accommodation and G.H. Gong for assistance with fieldwork. This work was conducted from the Field Research Station for Tibetan Wildlife, which is administered by Wuhan University and Tibet University. Financial support was provided by National Sciences Foundation of China (Grant 30270216) and by the Oriental Bird Club Small Grant for Bird Conservation.

\section{References}

Badyaev, A.V. (1997) Avian life history variation along altitudinal gradients: an example with cardueline finches. Oecologia, 111, 365-374.

Bibby, C.J., Burgess, N.D. \& Hill, D.A. (1992) Bird Census Techniques. Academic Press, London, UK.

Brown, J.L. (1987) Helping and Communal Breeding in Birds. Princeton University Press, Princeton, USA.

Brown, J.L., Dow, D.D., Brown, E.R. \& Brown, S.D. (1983) Socio-ecology of the grey-crowned babbler: population structure, unit size and vegetation correlates. Behavioral Ecology and Sociobiology, 13, 115-124.

Cody, M. L. (1985) Habitat Selection in Birds. Academic Press, Orlando, USA.

Emlen, S.T. (1978) Cooperative breeding. In Behavioural Ecology: An Evolutionary Approach. 1st edition (eds J.R. Krebs \& N.B. Davies), pp. 97-120. Blackwell Scientific Publications, Oxford, UK.

Emlen, S.T. (1997) Predicting family dynamics in social vertebrates. In Behavioural Ecology: An Evolutionary Approach 4th Edition (eds J.R. Krebs \& N.B. Davies), pp. 228-253. Blackwell Scientific Publications, Oxford, UK.

Gaston, A.J. (1977) Social behaviour within groups of jungle babblers Turdoides jacobinus. Animal Behaviour, 25, 828-848.

Gaston, A.J. (1978a) Social behaviour of the yellow-eyed babbler Chrysomma sinensis. Ibis, 120, 361-364.

Gaston, A.J. (1978b) Ecology of the common babbler Turdoidae caudatus. Ibis, 120, 415-432.

Gaston, A.J. (1978c) Demography of the jungle babbler Turdoides striatus. Journal of Animal Ecology, 47, 845-870.

IUCN (2003) IUCN Red List of Threatened Species. IUCN, Gland, Switzerland [http:/ / www.redlist.org, accessed 16 June 2004].

Johnson, J.W. \& Wichern, D.W. (1992) Applied Multivariate Statistical Analysis. 3rd Edition. Prentice-Hall, Upper Saddle River, USA.

King, B.R. (1980) Social organization and behavior of the gray-crown babbler. Emu, 80, 59-76.

Li, B.S. (1988) An outline on development of the vegetation in geological periods. In Vegetation of Tibet (eds Institute of Botany of the Chinese Academy of Sciences \& Changchun Institute of Geography of the Chinese Academy of Sciences), pp. 23-40. Science Press, Beijing, China.

Li, D.H. (1984) On the zonal distribution and geographical relationship of Timaliidae species in Tibet plateau. Acta Biologica Plateau, Sinica, 4, 149-162.

Li, S., Dong, Y.X. \& Dong, G.R. (2001) Desertification and Sustainable Development in Qinghai-Tibet Plateau. China Tibetology Publishing House, Beijing, China.

Manly, B.F.J. (1998) Multivariate Statistical Methods. Chapman and Hall, London, UK. 
Miehe, G. (1996) On the connexion of vegetation dynamics with climatic changes in high Asia. Palaeogeography, Palaecoclimatology, Palaeoecology, 120, 5-24.

Monadjem, A, Owen-Smith, N. \& Kemp, A.C. (1995) Aspects of the breeding biology of the arrowmarked babbler Turdoides jardineii in South Africa. Ibis, 137, 515-518.

Niu, Y.F. (1999) A study on environmental problems in Qinghai-Tibet plateau. Progress in Geography, 18, 163-171.

Primack, R.B. (1993) Essentials of Conservation Biology. Sinauer Associates, Sunderland, USA.

Ralph, C.J., Fancy, S.G. \& Male, T.D. (1998) Demography of an introduced red-billed leiothrix population in Hawaii. Condor, 100, 468-473.

Stattersfield, A.J., Crosby, M.J., Long, A.J. \& Wege, D.C. (1998) Endemic Bird Areas of the World: Priority for Biodiversity Conservation. BirdLife International, Cambridge, UK.

Winkler, D. (2000) Forest ecosystem and conservation for forest biodiversity in Tibet. In Conservation and Management for Biodiversity in Tibet (eds Z. Lü \& J. Springer), pp. 53-58. China Forestry Publishing House, Beijing, China.

Wright, J. (1998) Helping-at-the-nest and group size in the Arabian babbler Turdoides squamiceps. Journal of Avian Biology, 29, 105-112.

Yang, X.M. \& Li, S.G. (1998) Study on ecology of David's laughing thrush Garrulax davidi. Chinese Journal of Zoology, 33, 35-37.

Yuan, X.W. \& Liu, Y.T. (1998) Cooperative breeding behavior of Taiwan yuhinas (Yuhinas brunneiceps). In Proceeding of $3 \mathrm{rd}$ Ornithological Symposium Between China Mainland and Taiwan (ed. Wild Bird Society of Taibei), pp. 91-110. Wild Bird Society of Taibei, Taiwan.

Zahavi, A. (1990) Arabian babblers: the quest for social status in a cooperative breeder. In Cooperative Breeding in Birds: Long-term Studies of Ecology and Behavior (eds P.B. Stacey \& W.D. Koenig), pp. 103-130. Cambridge University Press, Cambridge, UK.

Zhang, J.W. (1988) Ecological-Geographic distribution of the vegetation. In Vegetation of Tibet (eds Institute of Botany of the Chinese Academy of Sciences \& Changchun Institute of Geography of the Chinese Academy of Sciences), pp. 234-250. Science Press, Beijing, China.

Zheng, Z.X., Li, D.H., Wang, Z.X., Wang, Z.Y., Jiang, Z.H. \& Lu, T.C. (1983) The Avifauna of Tibet. Science Press, Beijing, China.

Zheng, Z.X., Zheng, B.L. \& Long, Z.Y. (1987) Fauna Sinica, Aves Vol. 11, Timaliinae. Science Press, Beijing, China.

\section{Biographical sketch}

Xin Lu carries out research on the ecology and conservation of birds in the alpine ecosystem around the mid-Yalong Zangbo River, Tibet, including the ecology and behaviour of Tibetan eared pheasants. In 2002 he established the Field Research Station for Tibetan Wildlife, which is administered by Wuhan University and Tibet University. 